\title{
La posmodernización de la tradición. Nuevos retos para la gestión del patrimonio
}

\section{Tradition and postmodernity: new challenges for the management of heritage}

\author{
Nieves HERRERO PÉREZ \\ Universidad de Santiago de Compostela \\ mnieves.herrero@usc.es
}

Recibido: 3 de febrero de 2011

Aceptado: 14 de marzo de 2011

\section{Resumen}

En el artículo se revisan algunas contribuciones del análisis de la posmodernidad poniendo de relieve su interés para el estudio del patrimonio cultural y tomando como ejemplo la peregrinación jacobea contemporánea. Siguiendo líneas trazadas por antropólogos, que trabajan en el ámbito del patrimonio cultural en Galicia, se hacen algunas propuestas que podrían contrarrestar los efectos reductivos del régimen de significación posmoderno sobre la producción cultural.

Palabras clave: patrimonio cultural, posmodernidad, peregrinación jacobea, turismo.

\begin{abstract}
This paper examines some recent contributions to the analysis of posmodernity and highlights their relevance for the study of cultural heritage using the contemporary jacobean pilgrimage as example. In line with anthropologists that work in the field of cultural heritage in Galicia, the author makes some proposals to counteract the reductive effects of the postmodern regime of signification on cultural production.
\end{abstract}

Keywords: heritage, postmodernity, jacobean pilgrimage, tourism.

Referencia normalizada: Herrero Pérez, N. (2011). La posmodernización de la tradición. Nuevos retos para la gestión del patrimonio. Revista de Antropología Social, 20, 293-307.

SUMARIO: 1. Introducción. 2. La desdiferenciación de la cultura. 3. La pérdida del sentido de la historia. 4. La peregrinación jacobea contemporánea, viaje posmoderno. 5. Algunas propuestas. 5. 1. La importancia del espacio local. 5. 2. Prestar atención al asociacionismo en torno al patrimonio. 5. 3. Desarrollar programas de educación patrimonial. 5. 4. Fomentar una cultura turística que cultive los aspectos humanos y educativos del viaje. 5. 5. Creación de titulaciones de Antropología en Galicia. 6. Conclusiones. 7. Referencias bibliográficas. 


\section{Introducción}

Constituye un lugar común situar en la modernidad el contexto histórico en el que se constituye el campo de lo que hoy conocemos como patrimonio cultural ${ }^{1}$. Al mismo tiempo, asistimos en la actualidad a una polémica intelectual, que se refleja en disciplinas muy diferentes, en torno a si la etapa que actualmente vivimos puede ser calificada como "posmoderna".

El concepto de posmodernidad es complejo y se entiende de maneras diferentes (Featherstone, 2000; Harvey, 2004), pero, sin entrar ahora en esa complejidad, pretendo tomarlo aquí en referencia a la asunción más general, compartida por diversos autores - algunos de ellos utilizan, sin embargo, otras expresiones como "modernidad tardía", en el caso de Anthony Giddens (1994, 1995)—, según la cual a finales del siglo veinte se han producido una serie de cambios socio-culturales que suponen el agotamiento para unos, la radicalización para otros, de los principios que sirvieron para definir la modernidad.

Algunas de las aportaciones de estos autores y, en particular, las que se refieren al análisis de la esfera cultural trazan, desde mi punto de vista, un marco conceptual relevante para abordar el patrimonio cultural. Este marco puede ayudarnos a detectar cambios que se pueden estar produciendo en este ámbito concreto de la producción cultural y a proponer líneas o estrategias de actuación. Para teóricos como Scott Lash, el posmodernismo es estrictamente cultural y lo entiende como "un nuevo paradigma cultural", como lo serían también "el modernismo, el realismo o el barroco y el gótico", y no como "un tipo de sociedad en el sentido en el que la gente habla de sociedad industrial o sociedad capitalista o sociedad moderna" (Lash, 1997:20). La tesis de Fredic Jameson, a la que me referiré después, es que el posmodernismo no es más que la lógica cultural del capitalismo avanzado (Jameson, 1991).

En este artículo he querido reflejar una exploración de algunos conceptos de autores que me parecen relevantes para el análisis del patrimonio cultural. Considero que estos conceptos ayudan a detectar los efectos que puede estar teniendo el paradigma cultural posmoderno sobre esta esfera concreta de la producción cultural y a proponer líneas o estrategias de actuación.

Estamos asistiendo a "una segunda ola intensiva de patrimonialización de la cultura" (Santamarina, 2005: 32), a un "segundo proceso de construcción patrimonial", que va unido a los procesos de globalización y en el que la "ecuación patrimonioidentidad nacional se ve remplazada por la de "patrimonio-venta-consuno", guiada por una lógica de mercados, y en la que el patrimonio se asocia cada vez más al turismo y a los medios masivos de comunicación, aunque también a la sostenibilidad y los derechos humanos (Rosas Mantecón, 1999: 49). Se alude aquí al carácter ambivalente de la posmodernidad, al que me referiré más adelante.

${ }^{1}$ El título de este artículo se inspira en la afirmación de Antonio Ariño (1999), según la cual el patrimonio cultural sería resultado de la modernización de la tradición, es decir, del tratamiento particular que esta época hace del pasado. 
Se trata de un nuevo contexto que suscita la reflexión acerca del papel de los profesionales que intervenimos de diversas maneras - teóricas o prácticas, directas o indirectas - en el patrimonio y que, en el marco del paradigma posmoderno, podemos denominar intermediarios culturales o especialistas simbólicos. Este es el nombre que reciben una serie de profesiones nuevas o renovadas, interesadas en educar a diversos públicos y ligadas a los procesos comunicativos, que son expresión típica de la cultura del consumo que analiza Mikel Featherstone (2000) y que tienen una función crucial en la sociedad actual (Bovone, 2001).

Podría parecer paradójico hablar de posmodernización en un contexto como en el que escribo, Galicia, en el que aún muy recientemente hemos alcanzado los parámetros clave que se han utilizado para definir la modernidad en algunos ámbitos como, por ejemplo, el económico. Por eso es necesario hacer alguna reserva con respecto a este diagnóstico. Mikel Featherstone señala que, cuando aludimos a estilos de vida o prácticas culturales posmodernos o de "régimen de significación postmoderno", no hablamos de algo generalizado, sino de tendencias que conviven con otras y que se dan desigualmente según los lugares y grupos sociales. Este mismo autor nos invita a estudiar con rigor la extensión diferencial de lo posmoderno tomando en cuenta las prácticas culturales reales (Featherstone, 2002: 28).

En esta misma línea, John Urry (2002: 77) nos advierte que el paradigma cultural "es un tipo ideal". Esto quiere decir que hay otros importantes elementos culturales que estarán presentes en una sociedad dada: premodernos, realistas, modernistas, etc. Así pues, muchos fenómenos culturales encarnan elementos de diferentes tipos ideales y las diferentes sociedades son más o menos posmodernas.

Mi interés por la teoría del posmodernismo proviene precisamente del análisis de la peregrinación jacobea contemporánea. En ella podemos observar con claridad, junto a prácticas que se inscriben en el catolicismo oficial —acabamos de recibir la visita del Papa como peregrino con motivo de la celebración del Año Santo-, otras que considero que pueden ser calificadas de posmodernas.

A continuación aludiré a dos rasgos o manifestaciones de la cultura posmoderna, haciendo referencia a su expresión en el ámbito del patrimonio cultural en general y, de modo particular, en prácticas actuales de la peregrinación jacobea.

\section{La desdiferenciación de la cultura}

En su obra Sociología del postmodernismo (1997), Lash se refiere a la desdiferenciación como un rasgo fundamental de este régimen de significación. Mientras que el modernismo implica la separación y diferenciación estructural de esferas de la sociedad, como pueden ser la ciencia, la moral o la estética, cada una regida por sus propios principios y normas, el posmodernismo supone una desdiferenciación entre ellas. Esta desdiferenciación afecta de manera especial a la esfera cultural, en la que se disuelven las fronteras, tanto entre la alta cultura y la cultura popular o de masas como entre las diferentes formas culturales. Así podemos comprobar cómo hoy en día se producen mezclas entre el arte, la fotografía, la música, el deporte, el turismo, la arquitectura, la compra, etc. 
Por otra parte, tal y como señala Jameson (1991), la cultura experimenta una prodigiosa extensión por todo el dominio de lo social, hasta tal punto que se puede decir que "todo se vuelve cultural". Este mismo autor sostiene que desde los comienzos de 1960 se produjo un desplazamiento de cara a una nueva era, en la que la producción de la cultura se integró en la producción de mercancías en general, siguiendo un proceso impulsado por la frenética urgencia por producir novas olas de presuntos bienes siempre novedosos - "desde los vestidos a los aviones"-, lo que confiere una función estructural creciente a la innovación y a la experimentación estéticas (Jameson, 1991:18).

Los componentes culturales permiten especificar y diferenciar todo tipo de productos asociando a ellos sensaciones, un elemento básico de lo que se conoce hoy en día como "márketing experiencial". Estos componentes se difunden en los medios de comunicación y en la televisión fundamentalmente a través de las imágenes.

El consumo cultural posmoderno se da de manera relevante en el turismo. Como señalan Chris Rojek y John Urry (1997: 5), hoy en día el turismo es una "práctica cultural"; el turismo y la cultura se solapan ampliamente, de manera que no se puede trazar una frontera clara entre ellos.

Las imágenes tienen un papel central en la sociedad contemporánea, saturan la trama de la vida diaria mediante su presencia en la publicidad, las exhibiciones, las actuaciones y los espectáculos urbanos y a través de ellas se produce una fascinación estética y una constante reelaboración de los deseos. Esta es la raíz de la estetización de la vida cotidiana, expresiva de la propia desdiferenciación del arte, que deja de ser un enclave de la realidad autónomo y todo, la misma realidad cotidiana y trivial, cae bajo el signo del arte y se vuelve estético.

El dominio de la imagen acaba desdibujando la frontera entre lo real y lo imaginario y dando paso a la preponderancia de las formas figurales de la cultura y a la espectacularización de la realidad, frente a las formas discursivas basadas en el dominio de la palabra. El resultado es la preponderancia del espectáculo sobre la narrativa, una cultura sin profundidad, dominada por el simulacro y la hiperrealidad, señalados por autores como Jean Baudrillard y Umberto Eco, constituida por copias de objetos frecuentemente producidos en masa y situados en contextos en los que se pierden sus usos y significados originales.

El flujo de imágenes, así como la propia libertad de elección y de ensamblaje de elementos por parte del consumidor, darán lugar a formas eclécticas en las que se refleja el pastiche, la fragmentación y el efecto collage, esto es, una yuxtaposición de componentes heterogéneos de conocimiento e información.

\section{La pérdida del sentido de la historia}

Esta característica de la posmodernidad fue señalada por diferentes autores que relacionan el fenómeno directamente con la estetización de la experiencia, de la que venimos hablando, y el derrumbe de la cadena ordenada de significantes. Esto promueve una historia sincrónica y sin profundidad que, en parte, es también consecuencia de la destrucción de las metanarrativas características de la modernidad, 
basadas en la confianza en la existencia de verdades objetivas sobre la realidad y el lugar del ser humano en ella.

La pérdida del sentido del pasado es igualmente resultado del dinamismo característico de la modernidad y del proceso de comprensión del espacio y del tiempo, efecto a su vez de las tecnologías de la información y la comunicación. La pérdida de confianza en el futuro así como la conciencia del riesgo están en la base de la "moderna nostalgia" y de las prácticas de conservación y defensa tanto de la naturaleza como de las manifestaciones culturales del pasado. La búsqueda de las raíces históricas sería, entre otros, un modo de procurar vínculos más seguros o valores más duraderos en un mundo cambiante. Como afirma Kevin Walsh en su obra The representation of the past. Museums and heritage in the post-modern world (1997), esta apelación a la nostalgia no es mala y puede ser usada como una especie de prefacio para establecer una implicación crítica con el pasado y la conciencia de sus vínculos con el presente.

El enfoque procesual y diacrónico, propio de las disciplinas históricas, analiza los aspectos económicos, culturales y políticos, así como la relación entre el pasado y la configuración del presente, y genera conciencia crítica. Sin embargo, el tratamiento posmoderno del pasado, dominado por la fragmentación, se centra en las superficies, niega el proceso y la diacronía y genera en realidad amnesia. Walsh comparte la afirmación de David Lowental (1998) de que la nostalgia es la memoria de la que se ha extraído el dolor y pone como ejemplo la musealización de industrias mineras, en las que se omite la explotación y el sufrimiento de los que trabajaron en ellas. La moderna nostalgia remite a un pasado ideal, y se basa en una versión aséptica, no de la historia, sino del patrimonio.

Walsh se sitúa en la línea crítica de Robert Hewison (1987), para quien la posmodernidad y la llamada "industria del patrimonio", que despuntó a comienzos de la década de 1970, están vinculados, ya que "ambos conspiran a fin de crear una pantalla superficial que se interponga entre nuestra vida presente y nuestra historia" (Hewison, 1987: 135). Como afirma el título de Lowental, "el pasado se vuelve un país extraño". Estamos condenados a un futuro sin raíces, sin historia real; el patrimonio media en nuestra historia como una instantánea efímera (Walsh, 1997: 145, 149). Vivimos cada vez más en un lugar patrimonio en el que el sentido del pasado cede su lugar a los mitos (Featherstone, 2000: 170).

Para Andreas Huyssen, el museo puede ser tomado como paradigma de las actividades culturales contemporáneas (2002: 43). En la postmodernidad el museo y sus objetos pierden su carácter aurático y ganan legitimidad nuevas formas de conservar y representar el pasado. El autor de En busca del futuro perdido nos habla, en este sentido, del entierro del museo como templo de las musas y bastión de la alta cultura (Huyssen, 2002: 50) y de su resurrección como espacio híbrido, mitad feria de atracciones y mitad grandes almacenes (2002: 42). El papel del museo como lugar de conservación elitista ha dado paso al museo como medio de masas, como marco de puesta en escena espectacular.

Walsh establece una relación entre la espectacularización y superficialización de la historia y las nuevas estrategias de presentación del patrimonio. Así, advierte de 
los riesgos de la empatía o de la interpretación y la recreación de acontecimientos como modos acríticos y peligrosos de interpretación. Relaciona los centros de interpretación con el posmodernismo por su énfasis en el espectáculo y en el entretenimiento más que en la educación; en ellos los medios de representación se convierten en elementos más importantes que el propio mensaje.

\section{La peregrinación jacobea contemporánea, viaje posmoderno}

Estos análisis del régimen de significación posmoderno me resultaron clarificadores para el análisis de la recuperación del Camino de Santiago y de las interrelaciones entre turismo y peregrinación que se expresan en la práctica de la realización del Camino a pie (Herrero, 2010).

La esfera religiosa no es ajena al proceso de desdiferenciación institucional posmoderna que también convierte a la religión en un "recurso cultural" (Lyon, 2002: 28). El capital simbólico religioso queda libre, diseminado, flotante (Hervieu-Léger, 1993) y adopta formas difusas, implícitas, culturales o seculares, a la carta. (Mardones, 1994: 166). La Iglesia Católica ve debilitada la interpretación y administración de esta peregrinación y otros actores sociales compiten por la apropiación de este capital simbólico: las Asociaciones de Amigos del Camino y las Administraciones Públicas.

La patrimonialización ${ }^{2}$ puede ser vista aquí como una forma de apropiación de este capital religioso que queda sometido a las reglas de la "cultura del consumo". Las medidas recuperadoras y promocionales de los itinerarios históricos y de la peregrinación, que estos nuevos actores llevan a cabo, dan como resultado una puesta a disposición de la estructura simbólica y ritual de la peregrinación, vinculada a la representación de la vida humana como un camino, una metáfora raíz de la cultura occidental "de la que vivimos", como dirían George Lakoff y Mark Johnson (1995), evocadora de múltiples significados. Las condiciones formales establecidas para la realización actual de la peregrinación —el caminar, los refugios, los itinerarios históricos-, que se relacionan directamente con esta estructura y sobre los que se construye el sentido de la continuidad con el pasado, actúan como elementos articuladores o agregadores de referentes de sentido y narrativas posmodernas referidas al cuerpo, a la naturaleza, a la historia, y a la autenticidad, que se actualizan y experimentan intensivamente durante la peregrinación.

Los "mediadores culturales" y los "especialistas simbólicos" se encargan de elaborar estas narrativas en distintos formatos como textos científicos, guías turísticas, páginas web, novelas, películas, etc., que son a su vez trasladados al mercado para su consumo por distintos agentes promocionales, tanto públicos como privados, y que se difunden entre amplios sectores de la población por medio de las tecnologías de la información y la comunicación. Cada uno puede elaborar libremente su propio "collage" a partir de teorías muy diversas y frecuentemente espurias desde el punto

${ }^{2}$ En el año 1987 el Camino de Santiago fue proclamado por el Consejo de Europa Primer Itinerario Cultural Europeo y en 1993 la UNESCO lo declaró Patrimonio de la Humanidad. 
de vista histórico, escogiendo entre Shirley Maclaine, Paulo Coello, el esoterismo, la psicoterapia alternativa, etc...

El sociólogo portugués Carlos Fortuna relaciona el turismo con la destrucción creadora de las identidades. Al contrario de lo que sucedía en la premodernidad, en la modernidad - y esto se acentúa en la posmodernidad - las identidades dejaron de ser estables y rígidas para volverse transitorias y plurales; éstas se muestran contingentes y remiten a una estructura personal, afectiva y cognoscitiva que es progresiva y continuamente reconstruida por los sujetos como un modo de adaptación a una sociedad crecientemente compleja y cambiante (Fortuna, 1998: 38). Esta adaptación se lleva a cabo hoy en día por medio de dispositivos simbólicos, representacionales, estéticos y performativos mediados por el consumo.

El análisis, que Fortuna lleva a cabo de las ruinas históricas, resulta aplicable a la experiencia del Camino de Santiago. Se trata de "espacios rituales" que propician la descolocación de la personalidad de los sujetos y permiten un nuevo recentramiento basado en la fuga del presente y el refugio en el pasado. Sin embargo, según este mismo autor, la experiencia no se basa en la captación del mensaje histórico de la ruina, sino en factores atemporales "como lo simbólico y el dramatismo de la historia" (Fortuna, 1998: 79). Se trataría pues de experiencias mediadas por la reflexividad estética, en la que el cuerpo enlaza con dimensiones importantes de la subjetividad. El concepto de reflexividad estética ofrece una clave muy interesante para analizar los cambios de sentido que se producen en relación con el cuerpo desde el marco sacrificial del catolicismo al marco de la estetización posmoderna.

La peregrinación jacobea representa un caso de patrimonialización en el que podemos observar las condiciones y límites de su transformación en su sometimiento a las leyes del mercado. Las Asociaciones de Amigos del Camino consideran que el "patrimonio inmaterial" del Camino reside en que la peregrinación pueda ser vivida como una experiencia espiritual — no necesariamente religiosa-, de renovación y transformación personal, y en la que el peregrino pueda experimentar valores como la solidaridad, el desprendimiento, la autosuperación y el esfuerzo que se están perdiendo en el mundo actual. Sin embargo, la posibilidad de esta experiencia tiene unas condiciones y unos límites de sostenibilidad y la masificación actual del Camino los están sobrepasando. Tanto la Iglesia como las Administraciones propician esta masificación al estar más interesados en la "imagen" de la peregrinación que en la "experiencia real" de los peregrinos. Para las Administraciones, el peregrino ofrece una "imagen de marca" para potenciar Galicia como destino turístico a través de los programas Xacobeos. El vínculo del Camino de Santiago con la construcción de la identidad europea, promovido desde las propias instancias políticas, permite a la Iglesia afirmar la impronta del cristianismo en esa misma identidad y legitimar su espacio en el proyecto europeo. Al mismo tiempo, las cifras de peregrinos que realizan el camino a pie, en ascenso año a año, son presentadas por la Iglesia como ejemplos de las inquietudes religiosas en el mundo actual. 


\section{Algunas propuestas}

La reflexividad es otra característica de la posmodernidad en la que se fundamenta su carácter ambivalente. Si, por una parte, destruye el carácter ilusorio con el que se habían planteado la consecución de muchos ideales, también ofrece nuevas claves para reformular las condiciones para conseguirlos. El concepto de modernidad reflexiva, propuesto por autores como Ulrich Beck, Giddens o Lash (2001), introduce un punto de vista constructivo en la línea del posmodernismo deconstructivo. La "modernidad reflexiva" supone la capacidad de la sociedad de tomarse a sí misma como objeto y de pensarse en términos de proyecto-consecuencia, apoyándose en la incorporación de conocimientos e información suministrada por los sistemas expertos. Se diferencia de la fase anterior de la modernidad en que las consecuencias del proyecto moderno - como por ejemplo el Holocausto- son pensadas como fuerzas exógenas, como elementos externos al sistema y sin conexión con decisiones y procesos del modelo de desarrollo asumido.

Según Laura Bovone, los nuevos intermediarios culturales expresan también la ambivalencia de la cultura posmoderna. Tienen un papel central "en el campo en el que se trabaja la batalla de la definición y de la forma de la cultura" (Bovone, 2001: 113), pero no tienen por qué ser los portadores de una lógica dominadora de clase o de "sutil manipulación", pudiendo ser los protagonistas de iniciativas políticas innovadoras.

A partir de diferentes propuestas, algunas de ellas referidas explícitamente a Galicia y formuladas por antropólogos que trabajan en el ámbito del patrimonio cultural en esta Comunidad Autónoma, podemos esbozar algunas líneas de convergencia, que contrarresten las fuertes tendencias del régimen de significación posmoderno a mercantilizar la cultura y a reducir sus complejas y múltiples dimensiones y relaciones con la vida humana.

\section{1. La importancia del espacio local}

Para Walsh la provisión de servicios patrimoniales y, más ampliamente, culturales a través del mercado niega implícitamente la idea de éstos como servicio público, algo que hay que potenciar. El autor se suma a la denuncia de que los procesos de patrimonialización, llevados a cabo en regiones deprimidas, no están pensados para dotar de servicios culturales a los habitantes, sino que están orientados por exigencias económicas y para actuar como elementos de atracción para los foráneos. La clave de un futuro exitoso para los museos debe basarse, según este autor, en la gestión local y en la idea de democracia local y servicio público, entendiendo por servicio público una provisión que se juzga esencial y crucial para la calidad de vida. La representación del pasado debe ser concebida como una forma de experiencia educativa. La provisión libre de estos servicios es algo crucial para cualquier democracia.

Walsh entiende los museos como facilitadores que deben proporcionar las destrezas que permitan a las personas leer su propio espacio, así como otros espacios que puedan visitar. Frente a la dictadura del fragmento, estas destrezas han de permitir "hacer conexiones", tomar en consideración los vínculos económicos, sociales 
y políticos entre las personas y los lugares. Podemos decirlo con el famoso título del libro de Kevin Lynch: las musealizacines y, en general, las intervenciones en el patrimonio deberían aportar las claves para saber interpretar De qué tiempo es este lugar (Lynch, 1975), porque, como este autor afirma, el establecimiento de la "imagen personal del tiempo" que "celebra el presente y establece conexiones con el pasado" es crucial para la estabilidad personal.

En el marco de la nueva museología y siguiendo la metáfora del museo como espejo de la comunidad, legada por Henry Rivière, Walsh concibe el museo como integrado y activo, enfocado al estudio del lugar a través de la síntesis aportada por disciplinas diversas, y declara que ha de implicar a la población en la producción de su pasado. Los museos, afirma, "deben evitar la insultante estetización de los objetos". Para él, los efectos del posmodernismo non son solamente un problema porque mercantilizan, sino también porque insultan, tanto al consumidor como a la comunidad.

Algunos análisis antropológicos del tratamiento, que en general se ha venido dando al patrimonio etnográfico en Galicia desde las instancias políticas oficiales, han denunciado "el uso político partidista" (Méndez Pérez, 2004), el "folklorismo de degustación" (Sierra Rodríguez, 1997), el "enfoque etnográfico arqueologista" que identifica la identidad con residuos del pasado rural (Pereiro y Vilar, 2008), y "el desmantelamiento de una memoria colectiva" (Vilar Alvárez, 2010).

En el trabajo titulado "Concepto y gestión del patrimonio local", Llorens Prats hace algunas propuestas que permitirían superar la situación que describen estos diagnósticos (Prats, 2005). Propone abandonar las políticas centradas en las grandes y costosas instalaciones, que a menudo no van acompañadas de programaciones a largo plazo ni dotación de profesionales ${ }^{3}$, y aporta algunas consideraciones importantes para fundamentar políticas eficaces de la gestión patrimonial en el ámbito local. Según este autor, el camino para convertir el patrimonio local en un instrumento abierto y de futuro pasa por dar prioridad al "capital humano". En este término incluye a la población pero también a los técnicos, antropólogos y otros científicos sociales, así como a otros agentes culturales locales implicados en el devenir comunitario. Se trata de que todos ellos trabajen conjuntamente en proyectos integrados - educativos, culturales y económicos- a largo plazo y vinculando el patrimonio a la reproducción social y no como refugio frente a los malos tiempos. Prats concibe al patrimonio local como "foro de la memoria", una memoria que debe ser escavada mediante el trabajo de campo y la participación.

Para Huyssen la clave para encontrar "el futuro perdido" reside también en "la memoria vivida, una memoria que es activa: tiene vida, y está encarnada en lo social, es decir, en individuos, familias, grupos, naciones y regiones. Esas son las me-

${ }^{3}$ La construcción de la Ciudad de la Cultura, cuyo autor es el arquitecto norteamericano Peter Eisenman, ha sido un tema relevante del debate cultural de Galicia en los últimos años. Las numerosas críticas se han centrado, además de en la elevada inversión que contrasta con la carencia de dotaciones y programaciones en los ámbitos locales, en la ausencia de contenidos y la consideración de la cultura como espectáculo que subyace al proyecto. 
morias necesarias para construir los diferentes futuros locales en el mundo global" (Huyssen, 2002: 39).

\section{2. Prestar atención al asociacionismo en torno al patrimonio}

El asociacionismo en torno al patrimonio es hoy muy importante en Galicia y, como en otros ámbitos, en él se expresan las lagunas y carencias en funciones y servicios que son competencia de las Administraciones.

Néstor García Canclini ya señaló la importancia de atender a las formas en que las personas se relacionan con el patrimonio (García Canclini, 1993). Las consideraciones de Ariño (2004) para el caso de Valencia son extensibles en muchos aspectos al contexto gallego. En el asociacionismo patrimonial se manifiesta un interés vital por el patrimonio, que lo vincula a la calidad de vida, la sociabilidad y la construcción de la identidad local.

En algunas ocasiones las propias asociaciones realizan las tareas de investigación que son imprescindibles para llevar adelante sus proyectos; en otras, buscan el asesoramiento de investigadores y otros especialistas. Los datos etnográficos e históricos, así como los procedimientos para la animación comunitaria, son elementos claves que determinan la calidad de los resultados y de sus efectos. Debería estudiarse el modo de establecer vínculos entre el asociacionismo patrimonial y las instituciones dedicadas a la investigación y la gestión del patrimonio, de cara a prestar asesoramiento y apoyo técnico en iniciativas patrimonializadoras.

Xaquín Rodriguez Campos, basándose precisamente en el concepto de reflexividad posmoderna y el carácter ambivalente del turismo (2009), ha puesto de relieve los efectos positivos de diversas iniciativas promovidas por asociaciones como impulsoras de proyectos turísticos fundados en el patrimonio local (Rodríguez Campos, 2006, 2010). El autor muestra el "trabajo de la imaginación cultural" que permite a localidades gallegas periféricas situarse en el mundo global, estableciendo lazos transnacionales con otras comunidades con raíces culturales comunes, y definir de este modo una identidad cultural fuerte con la que enfrentarse a los retos de la globalización.

\section{3. Desarrollar programas de educación patrimonial}

La reflexión y discusión sobre la importancia de la educación patrimonial fue abierta por Xerardo Pereiro y Santiago Prado (2008) en el X Congreso de la Federación de Asociaciones de Antropología, celebrado en Donosti. Se trata de una materia emergente, que promueven hoy instituciones como la UNESCO o el Consejo de Europa, ante el convencimiento de que cualquier medida de protección y promoción del patrimonio, para ser verdaderamente eficaz, debe ir acompañada de programas institucionales de educación patrimonial, es decir, de programas de educación y sensibilización en los valores del patrimonio dirigidos especialmente a las nuevas generaciones.

La idea de "ciudad educadora", que se está poniendo en práctica y trata de impulsar la Asociación Internacional de Ciudades Educadoras que nació en Bolonia en el año 1994, promueve integrar en una misma perspectiva la acción educativa de los 
distintos ámbitos y agentes educativos locales a partir del diálogo y de la colaboración. Una de estas acciones educativas deberá ser precisamente el conocimiento y la vivencia del territorio.

La filosofía de la ciudad educadora también comporta considerar que la educación de los niños, jóvenes y ciudadanos en general no es únicamente responsabilidad de los estamentos tradicionales - Estado, familia y escuela—, sino que también es de los ayuntamientos, las asociaciones, las industrias culturales, las empresas con voluntad educadora y de todas las instancias de la sociedad. Por eso hay que potenciar la formación de agentes educativos no escolares y el fortalecimiento del tejido asociativo.

Las acciones de identificación cultural y territorial son acciones de política cultural y educativa a largo plazo, que exigen diseños estratégicos (Caride Gómez, 2000: 43) que tracen objetivos y metodologías. Requieren, sobre todo, como apuntábamos siguiendo a Prats (2005), una fuerte inversión en capital humano para dotar a los departamentos implicados de técnicos cualificados que permitan configurar un equipo interdisciplinar, en el que los antropólogos deberían estar presentes junto a animadores socio-culturales, educadores sociales, bibliotecarios, etc.

La educación y la cultura son ámbitos mutuamente implicados y así deberían estarlo en las políticas públicas. La descoordinación administrativa que se produce frecuentemente en la actualidad entre estos dos ámbitos tiene que ver con el florecimiento de la "cultura ornamental", con la cultura del espectáculo y del consumo a la que me he referido (Trilla Bernet, 1993:273).

\section{4. Fomentar una cultura turística que cultive los aspectos humanos y educa-} tivos del viaje

Como señala José $M^{a}$ Valcuende del Río (2003), aunque la relación entre patrimonio y turismo es paradójica y conflictiva, sería irresponsable renunciar a un matrimonio entre ambos, aunque sea de conveniencia.

En las conclusiones del foro sobre patrimonio y turismo, coordinado por Xosé Manuel González Reboredo en el Museo do Pobo Galego en 2009, se reclamaba un enfoque del turismo que fuera más allá de la consideración económica y cultivara los aspectos educativos y humanos de esta actividad para recuperar el viaje, que Marc Augé nos dice, que ya no parece posible (1998). Se señalaba también aspectos fundamentales como el fomento de los códigos éticos propuestos por organizaciones como la OIT o el Consejo de Europa, la formación del personal, la salvaguardia del territorio y la sostenibilidad. Todos estos aspectos no pueden ser tomados, según se hace tantas veces, como fórmulas de fácil repetición, sino como bases teóricas y filosóficas de las labores de planificación y control por los organismos responsables.

Es preciso fomentar una cultura turística que cultive los aspectos educativos del turismo y lo considere como una experiencia humana enriquecedora, que ponga las bases de un turismo "en el que la cultura se imponga como garantía de las dimensiones humanas del viaje" (Hernàndez i Martí, 2005: 192). 


\section{5. Creación de titulaciones de Antropología en Galicia}

Como en cualquier otro ámbito, la cualificación y preparación de profesionales adecuados determinarán también los resultados de la gestión cultural y del patrimonio. Ésta exige equipos interdisciplinares, en los que no deberían faltar antropólogos y antropólogas que aporten su visión característica de la cultura, una visión holística que la vincula a las diversas funciones que desempeña en el seno de los grupos sociales y que atiende a los sentidos que le otorgan las personas.

La creación de titulaciones de Antropología en Galicia sigue estando pendiente. En la actualidad existen áreas de Antropología en las tres universidades de Galicia que imparten materias en diferentes titulaciones, pero el número de profesores con el que cuentan es escaso para poner en marcha autónomamente una titulación. El nuevo marco de ordenación universitaria, adaptado a Bolonia, ofrece posibilidades para configurar una titulación basada en la cooperación interuniversitaria. Con ello se pondría fin a una carencia, que contrasta con el temprano desarrollo que tuvieron estos estudios a principios del siglo pasado y con el importante papel que se concede al turismo cultural y al patrimonio etnográfico para el desarrollo económico de Galicia.

\section{Conclusiones}

El análisis de la posmodernidad y algunos de sus diagnósticos resultan útiles para comprender el régimen de significación posmoderno y el sometimiento de la producción cultural a las leyes del mercado. Esto implica una reducción tanto de las múltiples dimensiones de la cultura como de las diversas funciones que debería cumplir el patrimonio cultural en la actualidad. Estas tendencias reductivas pueden contrarrestarse con una serie de propuestas, que deberían ser tomadas en cuenta en las políticas educativas y culturales referidas a Galicia y en las que la visión holista propia de la Antropología Social tendría que ser un ingrediente a incorporar.

\section{Referencias bibliográficas}

ARIÑO, Antonio

1999 "Como lágrimas en la lluvia. El estatus de la tradición en la modernidad avanzada", en R. Ramos Torre y F. García Seijas (eds.), Globalización, riesgo, reflexividad. Tres temas de la teoría social contemporánea. Madrid: CIS, 167-188.

2004 "Patrimonio y cultura popular", en X. Bouzada Fernández (ed.), Cultura e participación. Santiago: Consello da Cultura Galega, 51-79.

AUGÉ, Marc

1998 El viaje imposible: el turismo y sus imágenes. Barcelona: Gedisa.

BECK, Ulrich; GIDDENS, Anthony; LASH, Scott

2001 Modernización reflexiva: política, tradición y estética en el orden social moderno. Madrid: Alianza. 
BOVONE, Laura

2001 "Os novos intermediarios culturais", en C. Fortuna (org.), Cidade, Cultura e Globalizaçao: Ensaios de Sociología. Oreiras: Celta, 105-120.

CARIDE, José Antonio

1993 "Diseño de políticas culturales y animación cultural de comunidades humanas", en M. A. Santos Rego, A. Requejo Osorio y A. Rodríguez Martínez (eds.), Educación para la innovación y la competitividad. Formación y ocupación en el año 2000. Santiago de Compostela: Xunta de Galicia, 303-318.

FEATHERSTONE, Mikel

2000 Cultura de consumo y posmodernismo. Buenos Aires: Amorrortu.

FORTUNA, Carlos

1998 "Las ciudades y las identidades: patrimonios, memorias y narrativas sociales". Alteridades, 8, 16: 61-74.

GARCÍA CANCLINI, Néstor

1993 "Los usos sociales del patrimonio cultural", en E. Florescano (ed.), El patrimonio cultural en México. México: F.C.E., 41-61.

GIDDENS, Anthony

1994 Consecuencias de la modernidad. Madrid: Alianza.

1995 Modernidad e identidad del yo. Barcelona: Península.

GONZÁLEZ REBOREDO, Xosé Manuel

2009 Turismo e identidade. Santiago de Compostela: Foros do Instituto de Estudos das Identidades, Museo do Pobo Galego.

HERNÀNDEZ I MARTÍ, Gil-Manuel

2005 "La difusión del patrimonio cultural y el turismo", en G-M Hernàndez i Martí, B. Santamarina Campos, A. Moncusí Ferré et al. (eds.), La memoria construida. Patrimonio cultural y modernidad. Valencia: Tirant lo Blanch, 159-192.

HERRERO, Nieves

2010 "Patrimonialización y movilidad posmoderna: la reconfiguración de la peregrinación jacobea”, en C. del Mármol, J. Frigolé y S. Narotzky (eds.), Los lindes del patrimonio. Consumo y valores del pasado. Barcelona: Icaria-Institut Cataà d'Antropologia, 127-145.

HERVIEU-LÉGER, Danièl (Org.)

1993 La Religion pour Mémoire. Paris: Editions du Cerf.

HEWISON, Robert

1987 The Heritage Industry. Britain in a climate of decline. London: Methuen.

HUYSSEN, Andreas

2002 En busca del futuro perdido. Cultura y memoria en tiempos de globalización. México: FCE. 
JAMESON, Fredric

1991 El posmodernismo o la lógica cultural del capitalismo avanzado. Barcelona: Paidós.

2004 La condición de la posmodernidad. Investigación sobre los orígenes del cambio cultural. Buenos Aires: Amorrortu.

LAKOFF, George; JOHNSON, Mark

1995 Metáforas de la vida cotidiana. Madrid: Cátedra.

LASH, Scott

1997 Sociología del postmodernismo. Buenos Aires: Amorrortu.

LYNCH, Kevin

1975 ¿De qué tiempo es este lugar?: para una nueva definición del ambiente. Barcelona: Gustavo Gili.

LYON, David

2002 Jesús en Disneylandia. La religión en la posmodernidad. Madrid: Cátedra.

MARDONES, José María

1994 Para comprender las nuevas formas de la religión. Estella: Verbo Divino.

MÉNDEZ PÉREZ, Lourdes

2004 Galicia en Europa, el lugar de las artes plásticas en la política cultural de la Xunta. Sada: Edicións do Castro.

PEREIRO, Xerardo; PRADO, Santiago; TAKENARA Hiroko (Coords.)

2008 "Patrimonios culturales: Educación e interpretación. Cruzando límites y produciendo alternativas", en XI Congreso de Antropología. San Sebastián: Ankulegui Antropología Elkartea.

PEREIRO, Xerardo; VILAR ÁLVAREZ, Manuel

2008 "Ethnographic Museums and essentialist representations of Galician identity". International Journal of Iberian Studies, 21, 2: 87-108.

PRATS, Llorens

2005 "Concepto y gestión del patrimonio local". Cuadernos de Antropología Social, 21: $17-35$.

RODRÍGUEZ CAMPOS, Xaquín S.

2006 "Tourism and cultural reflexivity in Galicia", en X. S. Rodríguez Campos y X. M. Santos Solla (eds.), Galicia \&Terranova \& Labrador. Santiago de Compostela: Universidade de Santiago de Compostela, 73-91.

2009 "Os perigos da cultura espectáculo: turismo e dientidade cultural”, en A. Medeiros y M. J. Ramos (coords.), Memoria e Artificio. Matéria do Patrimonio II. Lisboa: Sociedade de Geografía, 89-101.

2010 "Del patrimonio local a las comunidades transnacionales. Turismo y etnicidad en Galicia", en C. del Mármol, J. Frigolé y S. Narotzky (eds.), Los lindes del patrimonio. Consumo y valores del pasado. Barcelona: Icaria-Institut Cataà d'Antropologia, 85-103. 
ROJEK Chris; URRY John (Eds.)

2000 Touring cultures: transformations of travel and theory. Lodon: Routledge.

ROSAS MANTECÓN, Ana

1999 "La participación social en las nuevas políticas para el patrimonio cultural", en E. Aguilar Criado (coord.), Patrimonio etnológico: nuevas perspectivas de estudio. Sevilla: Consellería de Cultura-Junta de Andalucía, 32-51.

SANTAMARINA CAMPOS, Beatriz

2005 "Una aproximación al patrimonio cultural”, en G-M Hernàndez i Martí, B. Santamarina Campos, A. Moncusí Ferré et al. (eds.), La memoria construida. Patrimonio cultural y modernidad. Valencia: Tirant lo Blanch, 21-51.

SIERRA RODRÍGUEZ, Xosé Carlos

1997 "Procesos de patrimonialización en Galicia", en Galicia Antropoloxía, vol 29. A Coruña: Hércules Ediciones, 382-495.

TRILLA BERNET, Jaime

1993 "Las políticas culturales y las políticas educativas", en M. A. Santos Rego, A. Requejo Osorio y A. Rodríguez Martínez (eds.), Educación para la innovación y la competitividad. Formación y ocupación en el año 2000. Santiago de Compostela: Xunta de Galicia, 233-270.

URRY, John

2002 The Tourist Gaze. London: Sage Publications.

VALCUENDE DEL RÍO, José María

2003 "Algunas paradojas en torno a la vinculación entre patrimonio cultural y turismo", en Antropología y patrimonio: investigación, documentación e intervención. Sevilla: Junta de Andalucía-Comares Editorial, 96-109.

VILAR ÁLVAREZ, Manuel

2010 "O desmantelamento dunha memoria colectiva", en S. Prado Conde (coord.), Actas da Conferencia Internacional da tradición oral. Oralidade e patrimonio cultural, vol. II. Ourense: Concello de Ourense, 219-226.

WALSH, Kevin

1997 The representation of the past. Museums and heritage in the post-modern world. London: Routledge. 